\title{
Prevalence and characterisation of
} diagnostic error among 7-day allcause hospital medicine readmissions: a retrospective cohort study

\author{
Katie E Raffel (D) ,' Molly A Kantor, ${ }^{1}$ Peter Barish, ${ }^{1}$ Armond Esmaili, ${ }^{1}$ \\ Hana Lim, ${ }^{2}$ Feifei Xue, ${ }^{1}$ Sumant R Ranji ${ }^{2}$
}

- Additional material is published online only. To view please visit the journal online (http://dx.doi.org/10.1136/ bmjqs-2020-010896).

${ }^{1}$ Medicine, University of California San Francisco, San Francisco, California, USA

${ }^{2}$ Medicine, San Francisco General Hospital, San Francisco, California, USA

\section{Correspondence to}

Dr Katie E Raffel, Medicine, University of California San Francisco, San Francisco, CA, USA; Katie.Raffel@ucsf.edu

Received 17 January 2020 Revised 4 July 2020 Accepted 15 July 2020 Published Online First 4 August 2020

\section{Sinked}

- http://dx.doi.org/10.1136/ bmjqs-2020-011099

\section{Check for updates}

(c) Author(s) (or their employer(s)) 2020. No commercial re-use. See rights and permissions. Published by BMJ.

To cite: Raffel KE, Kantor MA, Barish P, et al. BMJ Qual Saf 2020;29:971-979.

\begin{abstract}
Background The prevalence and aetiology of diagnostic error among hospitalised adults is unknown, though likely contributes to patient morbidity and mortality. We aim to identify and characterise the prevalence and types of diagnostic error among patients readmitted within 7 days of hospital discharge. Methods Retrospective cohort study at a single urban academic hospital examining adult patients discharged from the medical service and readmitted to the same hospital within 7 days between January and December 2018. The primary outcome was diagnostic error presence, identified through two-physician adjudication using validated tools. Secondary outcomes included severity of error impact and characterisation of diagnostic process failures contributing to error. Results There were 391 cases of unplanned 7-day readmission (5.2\% of 7507 discharges), of which 376 $(96.2 \%)$ were reviewed. Twenty-one (5.6\%) admissions were found to contain at least one diagnostic error during the index admission. The most common problem areas in the diagnostic process included failure to order needed test(s) ( $n=11,52.4 \%)$, erroneous clinician interpretation of test(s) $(n=10,47.6 \%)$ and failure to consider the correct diagnosis $(n=8,38.1 \%)$. Nineteen $(90.5 \%)$ of the diagnostic errors resulted in moderate clinical impact, primarily due to short-term morbidity or contribution to the readmission.

Conclusion The prevalence of diagnostic error among 7-day medical readmissions was $5.6 \%$. The most common drivers of diagnostic error were related to clinician diagnostic reasoning. Efforts to reduce diagnostic error should include strategies to augment diagnostic reasoning and improve clinician decisionmaking around diagnostic studies.
\end{abstract}

\section{BACKGROUND}

Diagnostic error is responsible for tens of thousands of preventable deaths each year. ${ }^{1}$ In hospitalised patients, diagnostic error accounts for $5 \%-18 \%$ of all adverse events and may contribute to as many as $50 \%$ of adverse events resulting in transfer to a higher level of care or death. $^{2-8}$ These studies potentially underestimate diagnostic error prevalence, as they do not use validated tools to screen for diagnostic error and use variable methods to discern causes of error. The burden and types of diagnostic error among hospitalised adults warrant further characterisation, as challenges with diagnostic error measurement have stymied systematic identification of diagnostic errors and precluded effective system improvement aimed at reducing this harm. ${ }^{129-11}$

Among hospitalised patients, those readmitted to the hospital within 7 days of discharge may represent a population enhanced for diagnostic error, as readmissions in this cohort are more likely to be preventable and related to the index hospitalisation. ${ }^{12} 13$ A recent multicentre prospective cohort study of unplanned 7-day and 30-day readmissions found that missed diagnosis may have contributed to $10.6 \%$ of all-cause 7 -day readmissions. ${ }^{12}$ While this study found diagnostic error contributed to hospital readmissions, it did not characterise the missed diagnoses nor did it identify the root causes of diagnostic errors.

We aimed to define the prevalence of diagnostic error among hospitalised adult medical patients readmitted for any reason within 7 days of discharge and to characterise factors that contributed to diagnostic process failure through the use of a retrospective cohort study and two-clinician case review.

\section{METHODS}

\section{Setting and study population}

This retrospective cohort study took place on the hospital medicine service at a single urban 650-bed academic hospital. 
There are eight teaching and six direct care medicine services with an average daily census of approximately 140 patients (including 16 critically ill patients) and 7000 annual discharges. Patients are admitted either (1) directly by a primary teaching team, (2) by an afternoon or overnight clinician and then transferred to a primary team the following morning, or (3) by an alternative admitting service and subsequently transferred to a medicine primary team during the hospitalisation. There is an integrated electronic medical record as well as existing infrastructure for collecting the rate of 7-day readmissions as a part of a quality improvement initiative targeting readmission reduction. There are several other separate admitting services, including separate cardiology and neurology admitting services.

The study population included all adult patients discharged from both the teaching and direct care general medicine services and readmitted (defined as observation or inpatient status during either the index admission or readmission) within 7 days of discharge between January 2018 and December 2018 to any service. All medical record reviews were conducted between 1 February 2018 and 30 June 2019. Patients were excluded if they were discharged to home hospice after the index admission or had a planned readmission (such as for an elective surgical procedure).

\section{Physician reviewer and training}

Six board-certified internal medicine physicians served as reviewers. All participating physicians used a physician user guide and performed a minimum of three training reviews, followed by an all-team discussion to gain familiarity with the diagnostic error identification and characterisation research tools and to ensure alignment. Reviewers did not review admissions in which they cared for the patient.

\section{Adjudication and data collection}

A data analyst identified hospital medicine all-cause 7-day readmissions on a monthly basis using the existing readmission tracking infrastructure. Patient demographics and basic clinical information were obtained from the hospital's clinical database. Each case of readmission then underwent independent review by two physicians with the aim of identifying if a diagnostic error was present among any index admission complaint or finding (figure 1). This did not need to be the chief complaint or primary problem alone. The two reviewers evaluated the patient's electronic medical record focusing on the admission history and physical (H\&P) and discharge summary from the index admission, outpatient or emergency department visit notes between admissions, and the discharge summary and H\&P from the readmission. If there was evidence of a possible diagnostic error (defined as a missed opportunity to have made a timely and correct diagnosis based on available evidence), the medical record for the index admission was reviewed in further depth. Review included vital sign measurement, laboratory and microbiology test results, radiology and pathology reports, medication administration and all notes.

We used the validated Safer Dx tool, an 11-question instrument assessing the diagnostic process to detect diagnostic error, on all cases of 7-day readmission to first determine if a diagnostic error was present (online supplementary file 1$).{ }^{14}$ This tool evaluates five parts of the diagnostic process: (1) the patient-clinician encounter, (2) ordering of tests/referrals, (3) follow-up, (4) subspecialty and referral-specific factors, and (5) patient-related factors. The Safer Dx tool has been previously validated in the primary care and paediatric intensive care unit setting; however, recent recommendations have been released regarding its use in other healthcare settings. ${ }^{15}$ We adhered to these recommendations including developing a shared understanding of diagnostic error, defining the episode of care and evaluating the diagnostic process as opposed to outcome. The index admission was considered the episode of care under review. Reviewers focused only on information available during the index admission. Reviewers used the scoring on the Safer Dx tool to individually determine whether or not the reviewed case represented a case of diagnostic error. After completing their independent review, the physician pairs then adjudicated the case to achieve consensus on the presence of diagnostic error. This approach was intended to minimise subjectivity and hindsight bias, as it has been shown that diagnostic cognitive bias is more likely to be identified if the patient outcome was a harm event due to diagnostic error. ${ }^{16}$ If error was present, the degree of harm was determined based on definitions within the Safer Dx tool. ${ }^{14}$

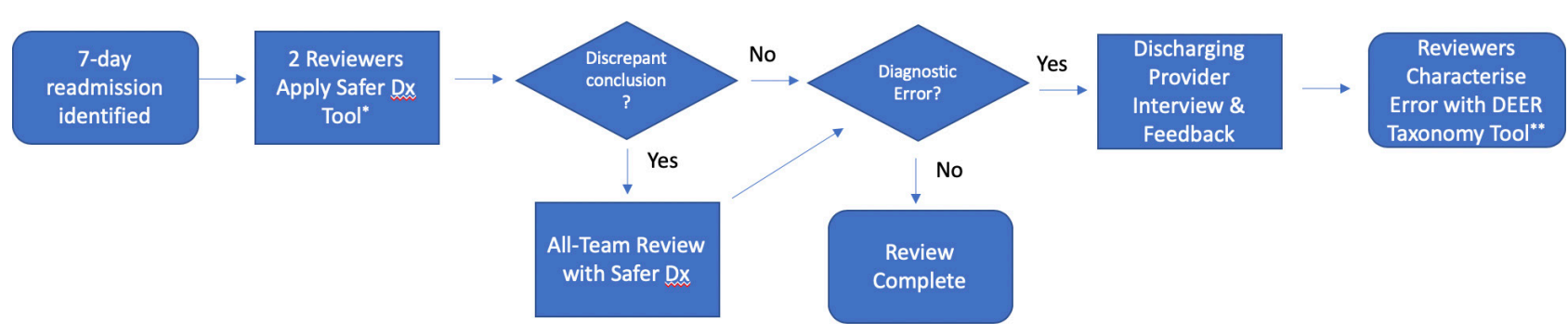

Figure 1 Diagnostic error case review process. *Adapted from Al-Mutairi et al ${ }^{14}$; see online supplementary figure 1. ${ }^{* *}$ Adapted from Schiff et al ${ }^{17}$; see online supplementary figure 2. DEER, Diagnostic Error and Evaluation Research. 


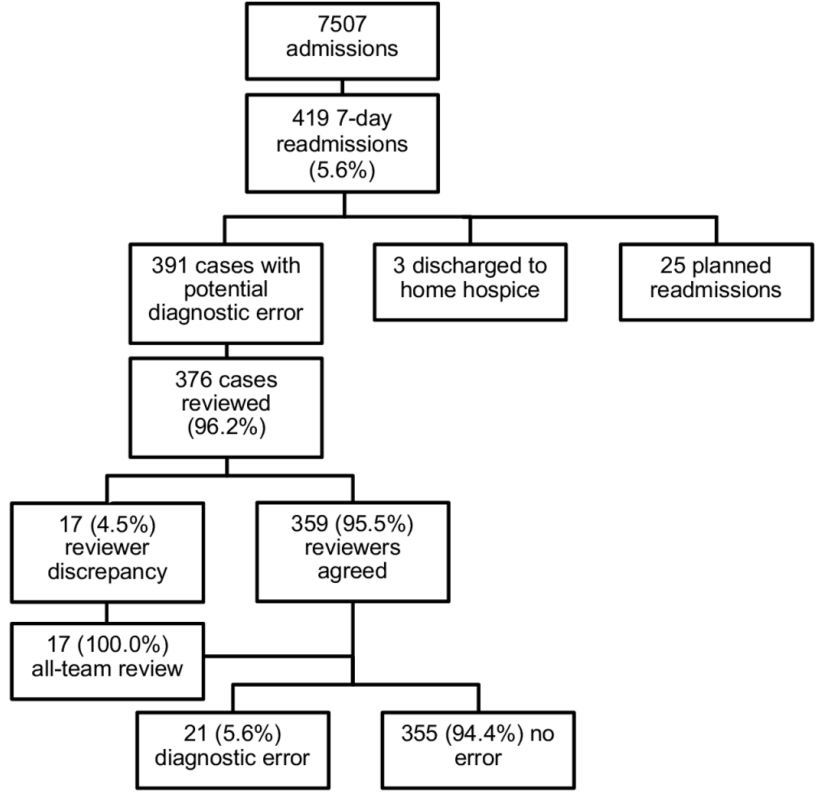

Figure 2 Seven-day readmission diagnostic error review process by admission numbers.

If there were a discrepancy in assessment of diagnostic error among the physician pairs, the case was independently reviewed by the larger six-physician review team and discussed at a monthly all-reviewer meeting until consensus was achieved. This monthly forum provided reviewers with an opportunity to discuss other challenging reviews and questions.

\section{Diagnostic error characterisation}

If a diagnostic error was identified by a reviewer, the reviewers then characterised the causes of the error by applying the Diagnostic Error and Evaluation Research (DEER) taxonomy tool, a six-item survey assessing the location and type of error in the diagnostic process ${ }^{17}$ (online supplementary file 2). This includes factors related to presentation, history, physical examination, testing, assessment, referral/consultation and follow-up. Reviewers then contacted the discharging clinician(s) from the index admission in order to better characterise the factors contributing to diagnostic error, beyond what could be recognised by electronic chart review alone. Providers were contacted via a standardised email to initiate a meeting in person or via phone call. During the meeting, reviewers discussed the admission with the discharging clinician(s) to elucidate further details of the clinical decision-making and circumstances that may have contributed to the error, using the DEER taxonomy survey as a guide. Interview content was captured in DEER taxonomy modification and was not otherwise recorded or qualitatively analysed.

\section{Data security and analysis}

Review data were recorded in Research Electronic Data Capture, a secure online database. Statistical analysis was performed using Stata (V.12.0) and SPSS V.23. Standard t-test and $\chi^{2}$ tests were used for comparison as appropriate. The inter-rater agreement of determination of error was expressed as a percentage of records for which there was agreement/disagreement and as a kappa statistic with 95\% CI.

\section{RESULTS}

\section{Cases reviewed and adjudicated}

During the study period, there were 7507 discharges with 419 (5.6\%) 7-day readmissions, a readmission rate comparable to other institutions ${ }^{18}$ (figure 2). Of these, 25 planned readmissions were excluded and three readmissions were excluded due to the discharge disposition on the index admission to home hospice. Of the remaining 391 cases of unplanned readmission, $376(96.2 \%)$ were reviewed. The 15 cases that were not reviewed were not initially identified on the monthly reports of 7-day readmissions due to index coding/billing anomaly. Reviewers agreed in 359 cases $(95.5 \%)$ and had discrepancy in 17 (4.5\%) cases; kappa statistic was moderate $(\kappa 0.62 ; 95 \% \mathrm{CI} 0.44$ to 0.79 ). Disagreement was more common among cases judged to contain diagnostic error $(n=4,19.0 \%)$ than those without error $(n=13,3.7 \%)(p<0.001)$. All 17 cases of discrepancy underwent all-team review. Of 21 identified cases of diagnostic error, clinician interview was performed in 19 (90.1\%); in two cases, the discharging providers had left the institution at the time of review.

\section{Patient demographics and clinical features}

Demographic data of admissions that contained and did not contain diagnostic error are shown in table 1 . No patient characteristic was statistically significantly different between both groups except for the Elixhauser comorbidity score, which was significantly lower for the index admissions with diagnostic error compared with those without diagnostic error (7.7 compared with $12.7, \mathrm{p}=0.045)$. There was no statistically significant difference between the admitting source, primary service or discharging team. The median length of stay was 2.9 days for patients experiencing error and 4.3 days for patients not experiencing error $(p=0.08)$. Fewer than half of the patients were directly admitted by the primary team in both groups $(p=0.71)$. The breakdown of disposition was similar among both groups $(\mathrm{p}=0.44)$.

\section{Presence of diagnostic error, diagnosis and impact}

Of the 21 identified diagnostic errors, 19 (90.5\%) had moderate impact, such as short-term morbidity, increased length of stay or required an invasive procedure. No error had major impact (defined as death, life-threatening event or permanent disability). Two $(9.5 \%)$ identified errors were judged to have no impact. A heterogeneity of diagnoses were represented among the identified errors (table 2). 


\section{Original research}

Table 1 Patient demographics and clinical characteristics according to presence of diagnostic error, among 376 patents readmitted within 7 days of discharge

\begin{tabular}{|c|c|c|c|}
\hline Characteristic & $\begin{array}{l}\text { Index admissions with } \\
\text { diagnostic error }(n=21)\end{array}$ & $\begin{array}{l}\text { Index admissions without } \\
\text { diagnostic error }(n=355)\end{array}$ & $P$ value \\
\hline Mean age, years (SD) & $63.7(19.1)$ & $60.3(19.2)$ & 0.44 \\
\hline Female sex (\%) & $10(47.6)$ & $184(51.8)$ & 0.71 \\
\hline Length of stay (days) & & & 0.08 \\
\hline Mean (SD) & $7.6(14.2)$ & $6.7(6.9)$ & \\
\hline Median (25-75 percentiles) & $2.9(2.1-4.9)$ & $4.3(2.5-8.0)$ & \\
\hline Length of ICU stay (days) & & & 0.63 \\
\hline Mean (SD) & $0.8(2.5)$ & $0.7(2.5)$ & \\
\hline Median (25-75 percentiles) & $0(0-0)$ & $0(0-0)$ & \\
\hline Primary race (\%) & & & 0.95 \\
\hline Asian & $4(19.1)$ & $76(21.4)$ & \\
\hline Black or African-American & $3(14.3)$ & $66(18.6)$ & \\
\hline Hispanic or Latino & $2(9.5)$ & $40(11.3)$ & \\
\hline White or Caucasian & $11(52.4)$ & $153(43.1)$ & \\
\hline Other & $1(4.8)$ & $20(5.6)$ & \\
\hline English as primary language (\%) & $18(85.7)$ & $296(83.4)$ & 0.78 \\
\hline Insurance coverage type (\%) & & & 0.73 \\
\hline Medicare & $9(42.9)$ & $181(51.0)$ & \\
\hline Medi-Cal & $8(38.1)$ & $97(27.3)$ & \\
\hline Private insurance & $4(19.1)$ & $74(20.9)$ & \\
\hline Self-pay & $0(0)$ & $3(0.9)$ & \\
\hline Admitting service (\%) & & & 0.96 \\
\hline Hospital medicine & $20(95.2)$ & $338(95.5)$ & \\
\hline Other & $1(4.8)$ & $16(4.5)$ & \\
\hline Admitting source (\%) & & & 0.50 \\
\hline Direct admission & $0(0)$ & $24(6.8)$ & \\
\hline Emergency department & $19(90.5)$ & $271(76.3)$ & \\
\hline Outside transfer & $1(4.8)$ & $26(7.3)$ & \\
\hline Other or unknown & $1(4.8)$ & $34(9.6)$ & \\
\hline Admitted by primary team (\%) & $8(38.1)$ & $150(42.3)$ & 0.71 \\
\hline Discharging team $(\%)$ & & & 0.08 \\
\hline Teaching team & $11(52.4)$ & $250(70.4)$ & \\
\hline Direct care team & $10(47.6)$ & $105(29.6)$ & \\
\hline Disposition (\%) & & & 0.44 \\
\hline Home & $10(47.6)$ & $179(50.4)$ & \\
\hline Home with services & $3(14.3)$ & $90(25.4)$ & \\
\hline Assisted living/intermediate care facility & $0(0)$ & $7(2.0)$ & \\
\hline Skilled nursing facility & $5(23.8)$ & $52(14.7)$ & \\
\hline Against medical advice & $3(14.3)$ & $22(6.2)$ & \\
\hline Other & $0(0)$ & $5(1.4)$ & \\
\hline Elixhauser comorbidity score, mean (SD) & $7.7(11.7)$ & $12.7(11.9)$ & 0.045 \\
\hline Elixhauser readmission score, mean (SD) & $21.8(18.0)$ & $25.6(17.4)$ & 0.09 \\
\hline
\end{tabular}

ICU, intensive care unit.

\section{Characterisation of factors contributing to error}

Factors contributing to diagnostic error (ie, root causes) stemmed from all six domains of the diagnostic process, as categorised by the DEER taxonomy (table 2). For a given diagnostic error, there was a mean of $4.7(\mathrm{SD}=2.1)$ and median of 5 contributing factors, from a variety of domains.
Factors within testing and clinician assessment were the most common; 19 (90.5\%) cases of error involved at least one contributing factor within the testing domain (eg, erroneous laboratory/radiology order/interpretation) and 19 (90.5\%) cases of error involved at least one contributing factor within the clinician assessment domain (eg, erroneous differential 
Table 2 Diagnostic error classification: factors contributing to diagnostic error, by DEER taxonomy category

\begin{tabular}{|c|c|c|c|c|c|c|c|c|}
\hline $\begin{array}{l}\text { Initial diagnosis (index } \\
\text { admission) }\end{array}$ & $\begin{array}{l}\text { Final diagnosis } \\
\text { (readmission) }\end{array}$ & $\mathrm{A} / \mathrm{P}$ & History & PE & Tests & Assessment & Ref/Con & $\begin{array}{l}\text { Follow- } \\
\text { up }\end{array}$ \\
\hline \multicolumn{9}{|l|}{ Neurological } \\
\hline Encephalopathy & Ceftriaxone-induced encephalopathy & & $x$ & & & $x$ & & \\
\hline \multicolumn{9}{|l|}{ Head and neck } \\
\hline Pharyngitis & Peritonsillar abscess (ID) & & $x$ & $x$ & $x$ & $x$ & $x$ & \\
\hline \multicolumn{9}{|l|}{ Cardiac } \\
\hline Bacteraemia & Endocarditis (ID) & $X$ & & $x$ & $x$ & $x$ & & \\
\hline Malignancy, compression fractures & Endocarditis, osteomyelitis, discitis (ID) & & $x$ & $x$ & $x$ & $x$ & & \\
\hline Dyspnoea & Heart failure (V) & & & $x$ & $\mathrm{X}$ & $x$ & & \\
\hline \multicolumn{9}{|l|}{ Pulmonary } \\
\hline Postobstructive pneumonia & COPD exacerbation & & & & $x$ & $x$ & & \\
\hline Bacteraemia, pneumonia & Empyema (ID) & $x$ & $x$ & & $x$ & $x$ & & \\
\hline Lung mass & Pneumonia (ID) & & $x$ & & $x$ & $x$ & & \\
\hline Urinary tract infection & Pulmonary embolism (V) & & & $x$ & $x$ & $x$ & & \\
\hline \multicolumn{9}{|l|}{ Renal } \\
\hline Hypovolaemic hyponatraemia & $\begin{array}{l}\text { Syndrome of inappropriate secretion } \\
\text { of } A D H\end{array}$ & & $x$ & & $X$ & $X$ & $X$ & \\
\hline
\end{tabular}

\section{Gastrointestinal}

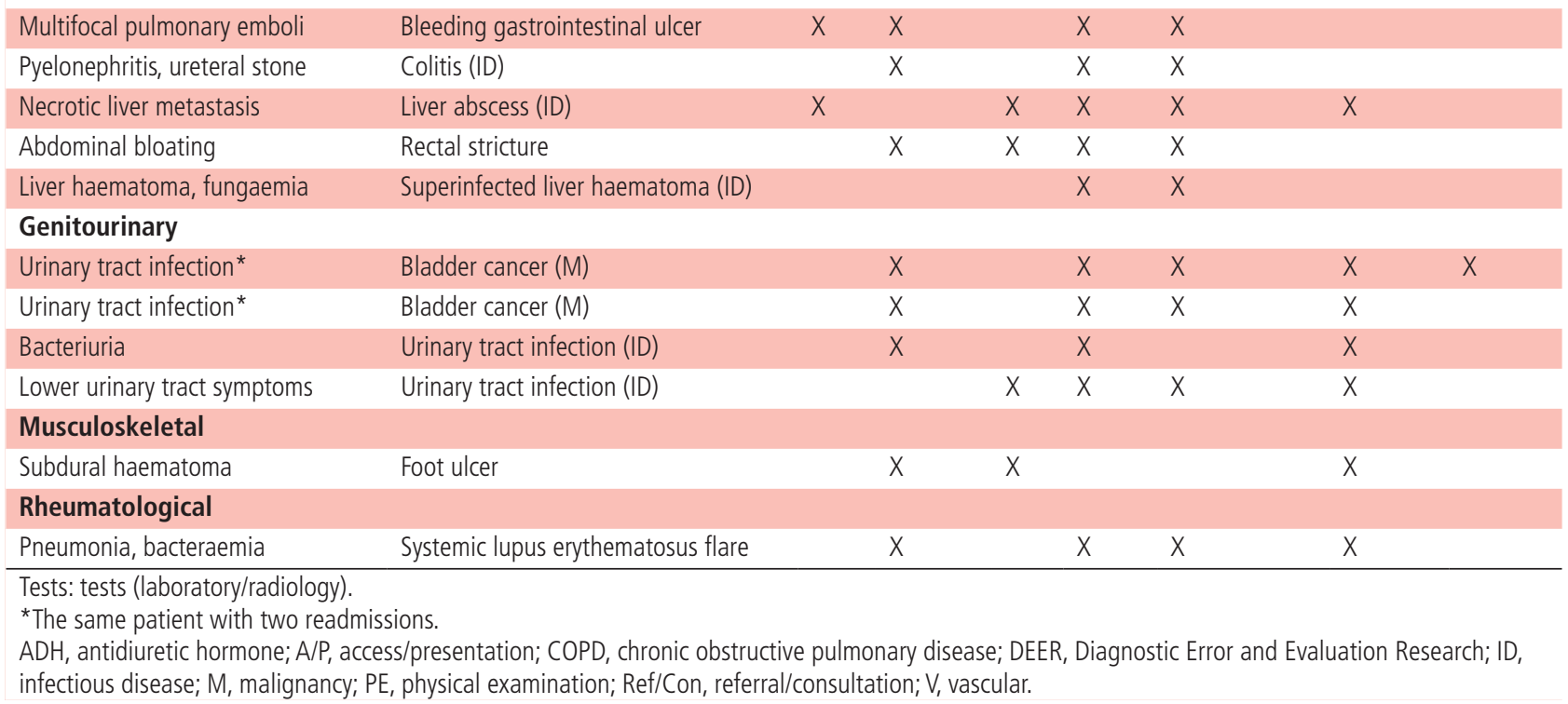

diagnosis development and prioritisation). Within the testing domain, failure to order needed tests(s) $(n=11$ $(52.4 \%))$ and erroneous clinician interpretation of test $(\mathrm{n}=10(47.6 \%))$ were the most common factors contributing to diagnostic error (figure 3). Within clinician assessment, the failure to consider the correct diagnosis was the most common factor contributing to error $(\mathrm{n}=8(38.1 \%))$. Representative examples of these errors are included in table 3.

\section{DISCUSSION}

Diagnostic error was present in $5.6 \%$ of patients readmitted within 7 days after discharge from an inpatient hospital medicine service, a relatively low though notable prevalence. This is a lower prevalence of error than that seen among inpatient adverse events, though this may be expected given that clinical stability at discharge and multifactorial causes of readmission, may make readmission a less specific trigger for diagnostic error identification. ${ }^{2-8}$ Patients readmitted with and without diagnostic error shared similar demographics, and we did not find evidence for specific patient factors contributing to readmission. While patients with a lower Elixhauser comorbidity score (7.7 vs $12.7, p=0.045$ ) were over-represented in our diagnostic error cohort, the Elixhauser readmission scores did not vary between the two groups. Given the similar factors accounted for in these two medical complexity scores and our low numbers of diagnostic errors, the significance of association between lower comorbidity score and diagnostic error is unclear. The identified diagnostic errors involved a wide variety of diagnoses and resulted from errors in multiple different domains of the diagnostic process. Nearly 


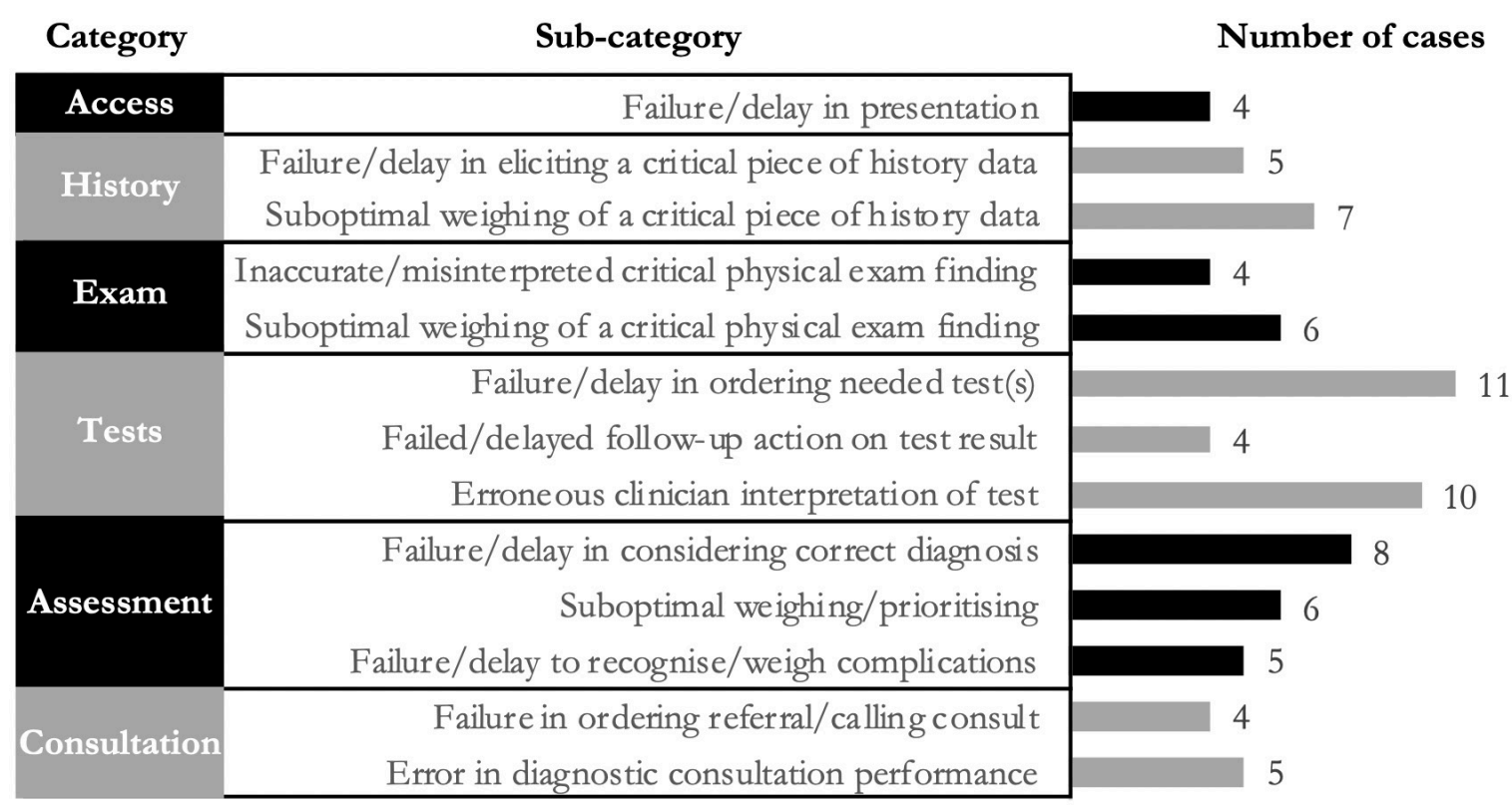

Figure 3 Top factors contributing to diagnostic error, by Diagnostic Error and Evaluation Research (DEER) taxonomy category and subcategory. Access: access to care/timing of presentation; History: history attainment; Exam: vitals and physical examination; Tests: laboratory/radiology ordering, reporting, interpretation; Assessment: clinician reasoning, differential diagnosis formation and prioritisation; Consultation: referral and consultation process.

all of these cases represented moderate patient harm, including short-term morbidity such as prolonged encephalopathy or invasive procedures such as chest tube placement or abscess drain.

The diagnostic errors in our study highlighted the diversity and complexity of general hospital medicine, representing 19 unique diagnoses. Nearly half of the cases $(n=10,47.6 \%)$ were within the broader category of infectious disease, though the organ systems involved varied. This may reflect the hospital medicine case mix at our institution, as patients admitted with vascular events, another set of commonly missed diagnoses, are typically admitted to primary cardiology and neurology services. ${ }^{19}$ Further, the non-specific signs and symptoms as well as non-specific testing associated with infection may make this a difficult diagnosis among medically complex patients. The majority of cases $(n=15 / 21)$ represented a change of the provisional diagnosis for a given chief complaint on index admission (eg, dyspnoea attributed to acute on chronic obstructive pulmonary disease when in fact it was secondary to acute on chronic heart failure). However, a notable minority of these diagnoses $(n=6 / 21)$ were complications of the primary problem (eg, Staphylococcus aureus empyema in the setting of $S$. aureus bacteraemia) or treatment course (eg, bleeding/gastric ulcer bleed after anticoagulation initiated for pulmonary embolism or ceftriaxone-induced encephalopathy in setting of treatment for enterococcal infection). Failure to identify a new diagnosis in this situation may have represented 'confirmation bias' on the part of the clinicians during the index admission, such as attributing new symptoms/findings to the known diagnosis rather than considering a new diagnosis or complication of the existing diagnosis. ${ }^{20}$

Diagnostic process factors contributing to a given diagnostic error were diverse; there were a mean of 4.7 contributing process errors in each case. The categories of the diagnostic process with the most sources of error were in tests (eg, radiology/laboratory) and assessment (eg, clinical reasoning). Within these domains, the contributing factors were related to various aspects of the clinical reasoning process, most commonly failure/delay in ordering needed test(s) and erroneous clinician interpretation of test(s) as well as inappropriate consideration or prioritisation of diagnoses. While studies of ambulatory diagnostic error cite factors within the patient-provider interaction (eg, H\&P exam) as a source of error, this was less contributory in our cases. This may potentially be a result of the difference in the diagnostic process in the two settings with increased time for the clinical encounter, enhanced caregiver presence and abundance of testing in the inpatient setting. ${ }^{21}$ Further, it was unlikely that a study of patients with 7-day readmissions would capture failures in follow-up as, by definition, the patient population did engage with the healthcare system within a week of discharge.

Our study represents an initial effort to describe diagnostic error among hospitalised adults in a structured approach and may have implications for improving diagnosis in the inpatient setting. Diagnostic errors are known to be due to both system causes and failures of clinical reasoning. In our small number of cases, errors 
Table 3 Contributing factors to diagnostic error, representative examples

\begin{tabular}{|c|c|c|c|}
\hline Example & $\begin{array}{l}\text { Contributing } \\
\text { factor, category }\end{array}$ & $\begin{array}{l}\text { Contributing factor, } \\
\text { subcategory }\end{array}$ & Final diagnosis \\
\hline $\begin{array}{l}\text { A patient with severe autism spectrum disorder and communication difficulties } \\
\text { presented to the emergency department with fever } 3 \text { days prior to the index } \\
\text { admission and was discharged home. Blood cultures later grew Enterococcus spp, } \\
\text { and the patient's family was advised to return to the hospital but initially declined. } \\
\text { After the patient ultimately presented, he was diagnosed with enterococcal } \\
\text { bacteraemia due to choledocholithiasis and endocarditis in the setting of } \\
\text { prolonged duration of untreated bacteraemia. }\end{array}$ & $\begin{array}{l}\text { Access/ } \\
\text { presentation }\end{array}$ & $\begin{array}{l}\text { Failure/delay in } \\
\text { presentation }\end{array}$ & Endocarditis \\
\hline $\begin{array}{l}\text { A patient with end-stage renal disease on haemodialysis was treated with } 6 \text { weeks } \\
\text { of intravenous ceftriaxone for Enterococcus endocarditis. She had prolonged } \\
\text { altered mental status, though was noted to be more alert on days following } \\
\text { haemodialysis. This was initially not appreciated by the care team. She was } \\
\text { subsequently diagnosed with ceftriaxone-induced encephalopathy. }\end{array}$ & History & $\begin{array}{l}\text { Suboptimal weighing of } \\
\text { a critical piece of history } \\
\text { data }\end{array}$ & $\begin{array}{l}\text { Ceftriaxone-induced } \\
\text { encephalopathy }\end{array}$ \\
\hline $\begin{array}{l}\text { A patient was initially admitted for generalised weakness and during this } \\
\text { admission was noted to have persistent hypoxia that was attributed to aspiration } \\
\text { or atelectasis; pulmonary embolism was considered but thought less likely. During } \\
\text { the admission, the patient had clear lungs on exam with vital signs notable for } \\
\text { hypoxia. On readmission, she re-presented with dyspnoea and was found to have } \\
\text { bilateral pulmonary emboli. }\end{array}$ & $\begin{array}{l}\text { Physical } \\
\text { examination }\end{array}$ & $\begin{array}{l}\text { Inaccurate/ } \\
\text { misinterpreted critical } \\
\text { physical exam finding }\end{array}$ & Pulmonary embolism \\
\hline $\begin{array}{l}\text { A patient was admitted for traumatic fractures and found to have a pulmonary } \\
\text { embolism for which he was anticoagulated. Patient's haemoglobin decreased } \\
\text { by } 2.5 \mathrm{~g} / \mathrm{L} \text { during admission. This was attributed to haemodilution, though other } \\
\text { cell lines did not decrease and the patient had received minimal fluid. He was } \\
\text { readmitted with acute gastrointestinal bleeding from a gastric ulcer. }\end{array}$ & $\begin{array}{l}\text { Tests (laboratory/ } \\
\text { radiology) }\end{array}$ & $\begin{array}{l}\text { Erroneous clinician } \\
\text { interpretation of test }\end{array}$ & Bleeding gastric ulcer \\
\hline $\begin{array}{l}\text { A patient's blood cultures grew Staphylococcus aureus and Streptococcus } \\
\text { anginosus. His admission chest X-ray showed a right lower lobe pulmonary } \\
\text { infiltrate and a small right pleural effusion that was tracking into the minor fissure. } \\
\text { He was readmitted with dyspnoea and hypoxia and found to have an empyema } \\
\text { with pleural fluid cultures growing S. aureus. }\end{array}$ & Assessment & $\begin{array}{l}\text { Failure/delay to } \\
\text { recognise/weigh } \\
\text { complications }\end{array}$ & Empyema \\
\hline $\begin{array}{l}\text { A patient presented with throat pain and fever. She was initially diagnosed with } \\
\text { pharyngitis. Otolaryngologist was not consulted during index admission. She was } \\
\text { readmitted with peritonsillar abscess requiring drainage. }\end{array}$ & $\begin{array}{l}\text { Referral/ } \\
\text { consultation }\end{array}$ & $\begin{array}{l}\text { Failure in ordering } \\
\text { referral/calling consult }\end{array}$ & Peritonsillar abscess \\
\hline $\begin{array}{l}\text { A patient with a chronic indwelling Foley catheter presented with an abnormal } \\
\text { urinalysis including pyuria and haematuria and was treated for urinary tract } \\
\text { infection. Concomitant hypercalcaemia prompted team to order an outpatient } \\
\text { referral to urology, but she was lost to follow-up. She was diagnosed with bladder } \\
\text { cancer over a month later. }\end{array}$ & Follow-up & $\begin{array}{l}\text { Failure/delay in timely } \\
\text { follow-up/rechecking of } \\
\text { patient }\end{array}$ & Bladder cancer \\
\hline
\end{tabular}

related to clinical reasoning were heavily represented. This is likely, in part, due to the emphasis on clinical reasoning factors in the DEER taxonomy tool. Nonetheless, these findings may show that system changes to improve diagnosis may need to focus on enhancing clinical reasoning regarding test ordering and interpretation and prioritisation of differential diagnosis.

Potential innovations supported by the root causes identified include (1) diagnostic testing and interpretation pathways developed through collaboration with laboratory and radiology professionals, ${ }^{22} 23$ (2) recognition of atypical clinical trajectories, including through use of technology, to prompt a diagnostic time out or further testing, ${ }^{22} 24$ (3) improved cognitive support including second opinions, collective intelligence, team-based care and clinical decision support, ${ }^{12526}$ or (4) development of reliable diagnostic outcome feedback for clinicians in order to allow for their personal diagnostic calibration. ${ }^{27}$ Notably, future study is warranted to understand the impact of these interventions on patient-level outcomes.

\section{Strengths and limitations}

This study is unique in that it included consecutive all-cause 7-day readmissions over the course of 1 year. Each case underwent two-physician review, a process well studied in the evaluation of adverse events using two previously validated tools, with additional insight provided by the index admission clinician. ${ }^{28}$ There were several limitations. First, this was a small single-site study at an academic medical centre and only included readmissions to the discharging institution. It is unclear if diagnostic error incidence may vary by health system setting, particularly as health systems may have differing access to specialty care and advanced diagnostics. However, the results were similar to the recent HOMERuN multisite 7-day readmission study. ${ }^{12}$ Second, the assessment of diagnostic error is subject to multiple potential biases. Reviewers may be prone to underassess error to avoid criticism of colleagues or misjudge error given hindsight bias and ultimate bad outcome (eg, readmission). Attempts to mitigate this bias were undertaken with the use of 
standardised and objective assessment tools, engagement of the index admission clinician and integration of adjudication process. However, the identification of diagnostic error remains difficult, as demonstrated by the higher prevalence of initial adjudicator disagreement among cases of diagnostic error. Notably, though the inter-rater agreement was comparable to that found in other adverse event studies. ${ }^{729} 30$ Finally, patients without readmission were not evaluated, so it is unknown how the prevalence of error among 7-day readmissions differs from the baseline rate of diagnostic error of all admitted patients in this sample.

\section{CONCLUSION}

Evaluation of unplanned 7-day readmissions using a two-physician diagnostic error review and adjudication process provides a mechanism for diagnostic error measurement. The overall prevalence of diagnostic error in this study was relatively low (5.6\%), though this may represent an underestimation as only patients readmitted to the same hospital were evaluated. Diagnostic process factors contributing to error included lapses in ordering and interpretation of studies as well as in differential diagnosis formation and prioritisation, highlighting the need for systemic efforts to improve clinician decision-making around diagnostic studies and to augment diagnostic reasoning to reduce patient harm.

\section{Acknowledgements Redacted to allow for triple-blind peer review.}

Contributors All authors listed have contributed sufficiently to the project to be included as authors, and all those who are qualified to be authors are listed in the author byline.

Funding Redacted to allow for triple-blind peer review.

Competing interests None declared.

Patient consent for publication Not required.

Ethics approval The institutional review board at (redacted) approved this study (IRB 18-24677).

Provenance and peer review Not commissioned; externally peer reviewed.

Data availability statement All data relevant to the study are included in the article or uploaded as supplementary information.

\section{ORCID iD}

Katie E Raffel http://orcid.org/0000-0002-5206-8862

\section{REFERENCES}

1 Balogh EP, Miller BT, Ball JR. Improving diagnosis in health care, 2016.

2 Forster AJ, Asmis TR, Clark HD, et al. Ottawa Hospital patient safety study: incidence and timing of adverse events in patients admitted to a Canadian teaching hospital. CMAJ 2004;170:1235-40.

3 Rafter N, Hickey A, Conroy RM, et al. The Irish national adverse events study (INAES): the frequency and nature of adverse events in Irish hospitals-a retrospective record review study. BMJ Qual Saf 2017;26:111-9.

4 Halfon P, Staines A, Burnand B. Adverse events related to hospital care: a retrospective medical records review in a Swiss Hospital. Int J Qual Heal Care 2017;29:527-33.
5 Soop M, Fryksmark U, Köster M, et al. The incidence of adverse events in Swedish hospitals: a retrospective medical record review study. Int J Qual Heal Care 2009;21:285-91.

6 Sari AB-A, Sheldon TA, Cracknell A, et al. Extent, nature and consequences of adverse events: results of a retrospective casenote review in a large NHS Hospital. Qual Saf Heal Care 2007;16:434-9.

7 Brennan TA, Leape LL, Laird NM, et al. Incidence of adverse events and negligence in hospitalized patients. Results of the Harvard medical practice study I. N Engl J Med 1991;324:370-6.

8 Zhang E, Hung S-C, Wu C-H, et al. Adverse event and error of unexpected life-threatening events within 24hours of ED admission. Am J Emerg Med 2017;35:479-83.

9 Newman-Toker DE, Pronovost PJ, Provonost P. Diagnostic errors--the next frontier for patient safety. JAMA 2009;301:1060-2.

10 Zwaan L, Singh $\mathrm{H}$. The challenges in defining and measuring diagnostic error. Diagnosis 2015;2:97-103.

11 Graber ML. The incidence of diagnostic error in medicine. BMJ Qual Saf 2013;22:ii21-7.

12 Graham KL, Auerbach AD, Schnipper JL, et al. Preventability of early versus late Hospital readmissions in a national cohort of general medicine patients. Ann Intern Med 2018;168:766-74.

13 Graham KL, Wilker EH, Howell MD, et al. Differences between early and late readmissions among patients: a cohort study. Ann Intern Med 2015;162:741-9.

14 Al-Mutairi A, Meyer AND, Thomas EJ, et al. Accuracy of the safer DX instrument to identify diagnostic errors in primary care. J Gen Intern Med 2016;31:602-8.

15 Singh H, Khanna A, Spitzmueller C, et al. Recommendations for using the revised safer DX instrument to help measure and improve diagnostic safety. Diagnosis 2019;6:315-23.

16 Zwaan L, Monteiro S, Sherbino J, et al. Is bias in the eye of the beholder? A vignette study to assess recognition of cognitive biases in clinical case workups. BMJ Qual Saf 2017;26:104-10.

17 Schiff GD, Kim S, Abrams R, et al. Diagnosing Diagnosis Errors: Lessons from a Multi-institutional Collaborative Project. In: Henriksen K, Battles JB, Marks ES, et al, eds. Advances in patient safety: from research to implementation (volume 2: concepts and methodology. Rockville (MD): Agency for Healthcare Research and Quality (US), 2005.

18 Fingar KR, Barrett ML, Jiang HJ. A Comparison of All-Cause 7-Day and 30-Day Readmissions, 2014. HCUP Statistical Brief \#230. Agency for Healthcare Research and Quality, Rockville, MD, 2017. Available: www.hcupus. ahrq.gov/ reports/statbriefs/sb230-7-Day-Versus-30-Day-Readmissions. pdf

19 Newman-Toker DE, Schaffer AC, Yu-Moe CW, et al. Serious misdiagnosis-related harms in malpractice claims: The "Big Three" - vascular events, infections, and cancers. Diagnosis 2019;6:227-40.

20 Croskerry P. The importance of cognitive errors in diagnosis and strategies to minimize them. Acad Med 2003;78:775-80.

21 Singh H, Giardina TD, Meyer AND, et al. Types and origins of diagnostic errors in primary care settings. JAMA Intern Med 2013;173:418-25.

22 Singh H, Graber ML, Kissam SM, et al. System-Related interventions to reduce diagnostic errors: a narrative review. BMJ Qual Saf 2012;21:160-70.

23 Hanscom R, Small M, Lambrecht A. Diagnostic accuracy: room for improvement, 2018. 
24 Huang GC, Kriegel G, Wheaton C, et al. Implementation of diagnostic pauses in the ambulatory setting. BMJ Qual Saf 2018;27:492-7.

25 Barnett ML, Boddupalli D, Nundy S, et al. Comparative accuracy of diagnosis by collective intelligence of multiple physicians vs individual physicians. JAMA Netw Open 2019;2:e190096.

26 Graber ML, Kissam S, Payne VL, et al. Cognitive interventions to reduce diagnostic error: a narrative review. BMJ Qual Saf 2012;21:535-57.

27 Meyer AND, Singh H. Calibrating how doctors think and seek information to minimise errors in diagnosis. BMJ Qual Saf 2017;26:436-8.
28 Leape LL, Brennan TA, Laird N, et al. The nature of adverse events in hospitalized patients results of the Harvard medical practice study II. vol 324, 2019. Available: https:/www-nejmorg.ucsf.idm.oclc.org/doi/pdf/ [Accessed 17 May 2019].

29 Sousa P, Uva AS, Serranheira F, et al. Estimating the incidence of adverse events in Portuguese hospitals: a contribution to improving quality and patient safety. BMC Health Serv Res 2014;14:6-11.

30 Zegers M, de Bruijne MC, Wagner C, et al. Adverse events and potentially preventable deaths in Dutch hospitals: results of a retrospective patient record review study. Qual Saf Health Care 2009;18:297-302. 